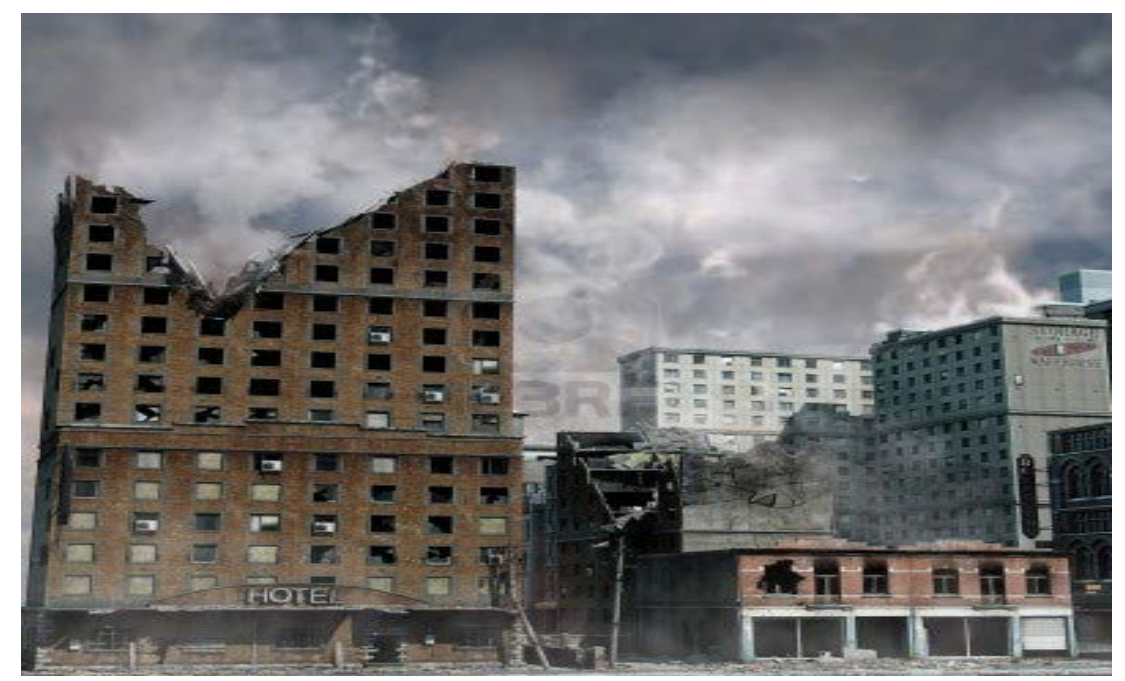

\title{
Residential Property Market Performance and Extreme Risk Measures
}

January 2017

Author

Dr. David M. Higgins

Birmingham City University

Birmingham, UK

david.higgins@bcu.ac.uk

Acknowledgments

The Author is grateful to Michael Cohen, pure mathematician, for his contribution and insights into the unorthodox theory of fractal geometry and tests for probability. 


\title{
Residential Property Market Performance and Extreme Risk Measures
}

\author{
By \\ Dr David M. Higgins \\ Birmingham City University
}

\begin{abstract}
Residential property is a popular investment option and has historically attracted many small individual investors. For Australian small residential property investors, debt financing is attractive as can lower the initial equity component, comply with a favourable tax structure (negative gearing) and on past evidence provide long term headline returns. A major concern with this approach is uncertainty, where stable assumptions cease to hold and there is concentrated negative price movement. This extreme downside volatility may not be fully reflected in traditional risk calculations.

This research studies 40 years of quarterly Melbourne established residential property market performance data for normal distribution features and signs of extreme downside risk. The results show that the normal bell curve distribution underestimated actual extreme values both by frequency and extent for ungeared residential property data. This is magnified as the gearing is increased to an extent where the outermost data point on $80 \%$ debt leverage shows an unrealistic probability of a 1 in 192 year event. Alternatively adopting the Cubic Power Law of returns, the probabilities of the most extreme event occurring drops to a realistic 1 in 38 year event.

In highlighting the challenges to measuring the impact of leverage on residential property market performance, the analysis of extreme downside risk should be separated from traditional standard deviation risk calculations. In recognising these two different types of risk, extreme downside risk has a magnified domino effect with increased gearing levels. Small negative price movement in housing values and interest rates can multiply the equity risk for the investor and can lead to financial ruin which is well beyond the standard deviation risk measure. This needs to be recognised and developed as there is evidence that extreme downside risk determinants are increasing by magnitude, frequency and impact.
\end{abstract}

Key words: Extreme risk, Standard deviation, Housing market performance, Power Law distribution 


\section{Residential Property Market Performance and Extreme Risk Measures}

\section{Introduction}

Housing is an important asset with a unique dual role, offering both social and economic benefits in providing shelter and as an attractive investment option. The physical fundamentals for residential property are easily understood by investors, driven by local demand from observed population growth and new supply scarcity based on planning approval data. This has led to residential property being a popular investment option which historically has attracted many small private landlord investors.

In Australia, alongside physical demand and supply attributes, residential property ongoing strong popularity can be linked to a favourable taxation regime, available debt funding and the use of investment properties as a retirement asset. Approximately 1.9 million of the 23 million Australian population own one or more investment properties, which represents almost $25 \%$ of the 9 million Australian residential dwellings (ABS 2015, Kohler and van der Merwe 2015).

Contributing to investor demand is the current low interest rate and the willingness of lenders to offer attractive debt packages with high gearing levels $-80 \%$ Loan to Value Ratio (LVR). For an investor, debt financing is attractive as can lower the initial equity component and provide long term headline returns. A major concern with this approach is that it works well under stable conditions - improving house prices and low interest rates. However when the stable assumptions cease to hold, house prices fall and interest rates increase, there is concentrated negative price movement. This can create a significant loss for an investor, compounded by leverage obligations with capital depreciation and regular mortgage payments.

Given the recent strength of investor demand for Australian housing and the appetite for debt funding, the characteristics and risk strategy of small investors property exposure warrant closer examination as the returns may not match the risk, specifically the impact of large negative price fluctuations. Like residential property, these major downside risk events are inherent to many investment markets, and are often outside the realms of regular expectations. Commonly referred to in literature as statistical outliers ( \pm 2 standard deviations), these downside risk events frequently have a combination of low predictability and large impact resulting in significant financial loss. Interestingly, whilst leading theorists and practitioners have recognised that the 
frequency and magnitude of these extreme events should be a key financial market consideration, there is no literature on the residential property market application.

This research studies 40 years of Melbourne quarterly residential property market performance data for signs of extreme downside risk. A metropolitan market was selected as residential markets across Australia can vary considerably based on local factors. For example, most recently Perth and Brisbane house prices have independently followed the global mining and energy commodity cycle. To compare with competing asset classes, a total return index was constructed and equity performance was examined with increased debt leverage levels. With the improved debt fuelled returns, the extreme downside risk is magnified. This requires further investigation by examining the probability distribution compared to a normal distribution curve. The application of a cubic power law distribution model from statistical physics is a robust method to identify the performance of an investment to the vulnerabilities of severe risk.

Following this introduction, Section Two provides a literature review covering the Australian house price performance, property investment lending and risk issues with extreme values and Power Law. Section Three details the selected residential property data and associated methodology. Section Four provides the empirical findings and the implications for the small investor and the wider finance community. The last section provides the concluding comments.

\section{Literature Review}

Much of housing investment literature is focused on how property behaves differently to competing financial assets (Case and Shiller 1989, and Bodman and Crosby 2004). In contrast, the literature in this paper examines both the disruptive drivers and measurements that lead to extreme residential performance risk with reference to a framework for residential property determinants, property investment loans and measures of extreme risks.

\section{Residential property determinants}

Changes in house prices can be affected by a number of external factors. These can be categorised into unexpected events, structural changes and core cyclical economic activity - see Figures 1 
Figure 1

Modelling the Economic Environment

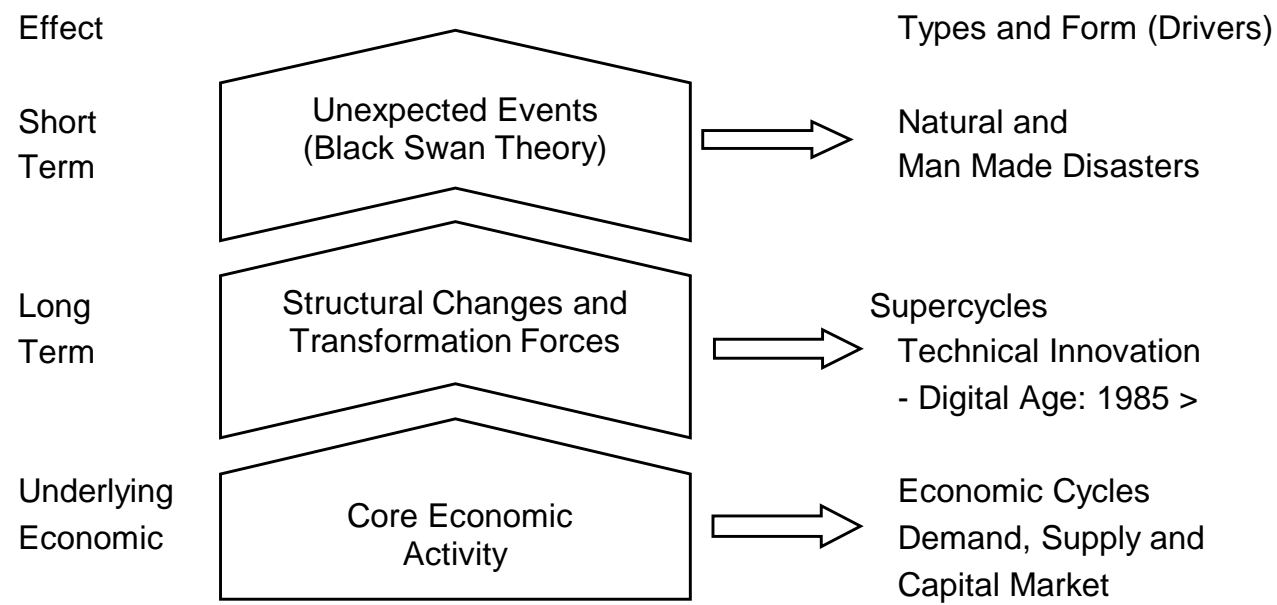

Figure 1 identifies key drivers of economic performance that may impact upon real estate modelling. In the past, leading underlying macroeconomic indicators have provided a good guide to future economic conditions and real estate performance. However, these forces do not exist in a vacuum, as emerging disruptive factors, both directly and indirectly, challenge core economic activity (Trahan and Krantz 2011).

Overlaid on the underlying economic environment are long term structural changes. These structural changes often initiated by policy decisions and innovation appear to have permanent far-reaching economic implications as they are unalike historical experiences and difficult to forecast. This is evident in the level of technical innovation created by the modern digital age, such as technological advances in artificial intelligence, biotechnology, robotics etc, which have left policymakers, business leaders and consumers scrambling to understand their full social, economic and ethical implications (Higgins 2015).

Furthermore, economic cycles and structural changes are clouded by extreme, unpredictable, short-lived events that include; natural catastrophes (superstorms, pandemics (SARS) and tsunamis etc), and man-made disasters (investment strategies (GFC), technological (Chernobyl) and acts of terrorism etc). These events can have enormous consequences on the wider economic environment and create uncertainty. They are often the origin of market crashes and can have a domino effect, leading to a cycle where those directly involved and the wider community incurs considerable losses. These clusters of negative price movement can vary in time alongside extended periods of stability (Buchanan 2013).

In detailing the framework, changes in house prices can be affected by the behavior of a number of underlying economic variables. Figure 2 shows the last 40 years of Melbourne established house prices, headline inflation (Melbourne CPI) and RBA indicative residential leading rates. 
Figure 2 Melbourne House Prices and Leading Economic Indicators

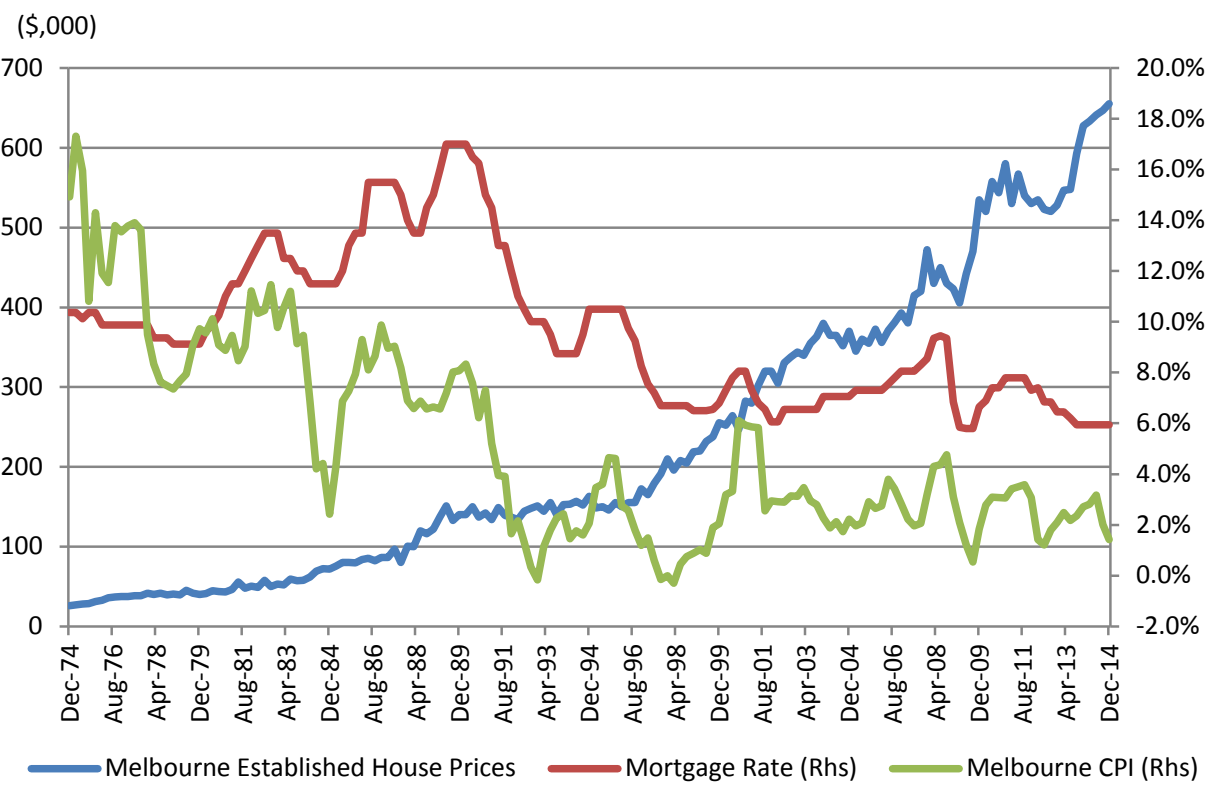

Source: REIV 2015, ABS 2015, RBA 2015

In detailing the past 40 years of Melbourne house prices, Figure 2 shows the contrast between the volatile inflation and interest rates and the stability in house prices during the 1970 s and early 1980s. This compares to the low inflation and low interest rates in the 1990s where strong Melbourne house prices growth was evident. In part, this was caused by financial sector deregulation with increased competition which allowed borrows improved access to credit and reduced costs (RBA 2014a).

According to Kohler and van der Merwe (2015) increased access to credit by Australian households contributed to the gap between exponential house prices growth and low interest rates. The trend is observed in the high household debt-to-income ratio fluctuating around $150 \%$ over the past decade. As with high debt levels, mortgage interest rate movement is a significant explanatory to house price fluctuations and so links the source of disruption in the capital markets to the housing landscape.

\section{Property Investment Loans}

Individual residential property assets are generally large in terms of transaction price. This high value threshold means that residential property investment requires considerably high levels of capital investment. Using only equity finance can limit investor opportunities for a diversified portfolio and lead to high specific property risk. Drawing upon debt finance enables available equity funds to be used across a range of investments and achieve diversification benefits. Such leverage can enhance expected returns as long as the return on investment exceeds cost of debt. 
Debt finance conditions placed on the property asset must be met to avoid default and its consequences (Higgins 2014).

In Australia, a large loan is attractive to small investors as debt servicing expenses are taxdeductible and so creating a strong incentive to take out interest only loans to buy an investment property. This is demonstrated in Australia with around 64\% of loan approvals to investors are interest-only, compared with $31 \%$ to owner-occupiers. The typical interest-only period on these loans is around five years, though up to 15-year period are also available (RBA 2014b).

During the loan period, increasing house prices can provide a healthy return to the investor. However, if housing prices should fall there is a risk the loan balance will exceed the property value and the investor could easily experience negative equity. Depending on market conditions, typically investors have a $80 \%$ loan to valuation ratios (LVRs) limit, driven in part by investors seeking to avoid the cost of lenders mortgage insurance which normally starts above this figure (RBA 2014b).

Measures of Extreme Risk

Financial market theory suggests that future value can be calculated from a normal distribution (bell curve) where most future values will be somewhere near the centre (tallest part of the curve), and further out from the centre peak the curve drops off quickly, indicating that large changes in price are less likely (Weatherall 2013). Plotted on the conventional bell curve, the standard deviation distribution is shown in Figure 3.

\section{Figure $3 \quad$ Normal Distribution}

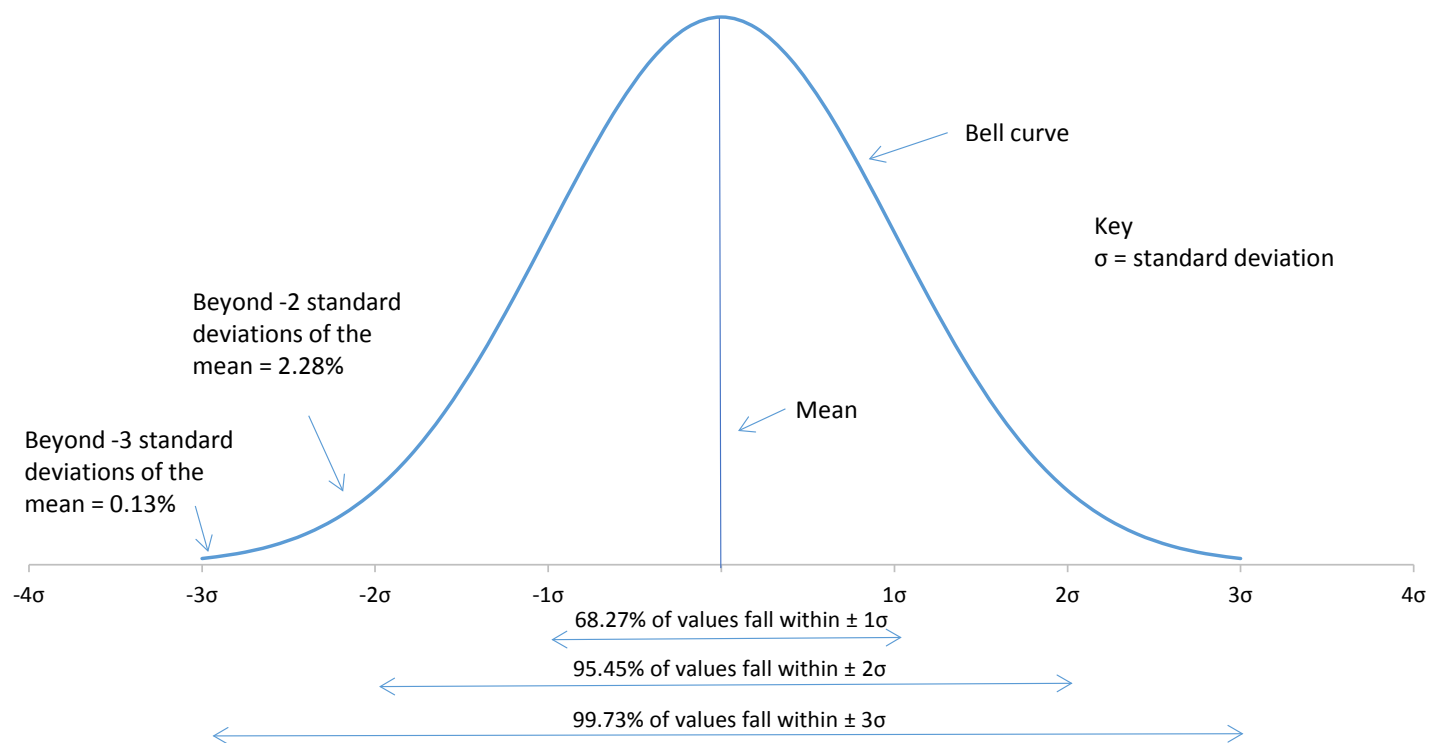


Figure 3 illustrates the bell curved shape of a normal distribution. The standard deviation " $\sigma$ " marks the location of the values, with $68.27 \%$ of the values within one standard deviation of the mean, similarly $95.45 \%$ of the values are within two standard deviation and nearly all (99.73\%) of the values are within three standard deviation. As the sigma " $\sigma$ " grows, the odds of being inside the bell curve rapidly approaches $100 \%$, while the odds of being outside, an "outlier" (beyond \pm 2 standard deviations), should be an extremely rare event (Wheelan 2013).

In defining the normal distribution on a bell curve, the possibility of unpredictable large deviations (outliers) are simply marginalised, because the data over-sampled the good times and undersample the bad. This situation can occur in the finance market with long stable periods providing extensive data close to the mean and then, although rare, severe instability with huge fluctuations creating booms and crashes. These extreme events far from the centre of the distribution are more regular than a normal distribution would predict and create, so called, "fat tailed" distributions (Mandelbrot and Hudson 2008).

Measures of extreme risk provide skewed distribution, as evident in the financial markets which rarely follow a normal bell shaped distribution. The higher frequency of extreme outcomes in the tails of the distribution may lead to an underestimation of risk. In such cases, Power Law may be a more appropriate model to measure fat-tailed distributions. This technique is often used in applications of extreme value theory as it overcomes many of the shortcomings of traditional financial stress testing (value at risk) models (Mandelbrot and Hudson 2008, Powell 2008).

In practical terms, conventional distribution calculations are best suited for a data series that exhibits mild and well-behaved randomness, as the difference between each point and the mean is squared and leads to an equitable scattering of points evenly around the mean. Power Law on the other hand, utilises fractal patterns which can relate intensity to frequency and is more suited for data series that exhibit irregular large movements. For investment strategies, Power Law can define the probability of a rare event, as it provides the parameter that determines the shape of the distribution, and therefore the likelihood of given extreme events. The Power Law exponent varies inversely with the fatness of the downside tail distribution; being the fatter the tail, the greater the likelihood of a given extreme loss (Mandelbrot and Hudson 2008, Powell 2009).

\section{Data and Methodology}

For this study, a quarterly 1970 to 2014 Melbourne median house price data series was created by combining the Real Estate Institute of Victoria (REIV) established median house price data with an extended BIS Shrapnel residential market database. The rent component is from the Melbourne consumer price inflation index (ABS catalogue no. 6401). Based on Heaney et al (2012) study, rental returns on private real estate were reduced by $12 \%$ to account for outgoings 
associated with managing residential real estate. This is based on Australian Taxation Office information on individual rental income and deductions. Although difficult to substantiate with no literature in this area, it does appears compatible with local real estate market evidence.

In the competitive Australian banking environment, residential property interest rate disclosure is sensitive data and difficult to source. However, on market evidence, the RBA publish an indicative house lending rate time series which can be a proxy for pricing of residential property debt for this research. In providing interest rate changes, there are several additional debt funding considerations including debt expiry profile, level of security and debt default process. In additional whilst this research selected the variable "floating" rate, interest rates can be fixed over the term of the loan, where future payments are known. The choice between fixed and floating interest rates is dependent on several factors, including the economic and financial environment and debt pricing mechanism adopted by the financier. This can be examined in a future paper.

According to Lux (2006), Power Law is a mathematical relationship between two quantities with a central theme that Power Law provides an exponential relationship that exhibits the property of scale invariance. There are various formulations and expressions with the simplest Power Law distribution showing the relationship between two variables, $X$ and $Y$, which be written as follows:

Equation 1

$$
Y=X \alpha^{k}
$$

In practice, few empirical data sets observe Power Law distributions for all values of $\mathrm{X}$. More often Power Law models apply to:

i. Extreme values that exhibit outlier status relative to the "goodness-of-fit" between the empirical and normal distributed data sets (Damodaran 2008, Lux 2006).

ii. Past extreme volatility in equity market returns were found to have a Power Law distribution with an exponent of three (3). The robustness of the findings across different stock markets has led to the term Cubic Power Law, and provides a simple model to scale low probability extreme events in the financial markets (Gabiax 2008, Mandelbrot and Taleb 2006).

As extreme price swings appear to be the norm in current financial markets, Power Law distributions can provide valuable information on equity market outliers. This needs to be examined relative to competing asset class returns, to see if extreme outliers exist and have features which follow the Power Law distribution. This research covers the key asset class of residential property. 


\section{Results}

The first step is to examine the quarterly investment performance of the Melbourne residential property market total return data with different gearing levels. Descriptive statistics provide a simple summary of the selected data as shown in Table 1.

Table 1

Descriptive Statistics

\begin{tabular}{lccccc}
\hline \multicolumn{5}{c}{ Melbourne Residential Total Returns with Lending Levels } \\
& Actual & $20 \%$ & $40 \%$ & $60 \%$ & $80 \%$ \\
\hline Mean & $4.0 \%$ & $4.4 \%$ & $5.1 \%$ & $6.5 \%$ & $10.7 \%$ \\
SD & $6.8 \%$ & $8.4 \%$ & $11.2 \%$ & $16.8 \%$ & $33.7 \%$ \\
SD-1 & $-2.8 \%$ & $-4.0 \%$ & $-6.1 \%$ & $-10.4 \%$ & $-23.0 \%$ \\
SD-2 & $-9.5 \%$ & $-12.5 \%$ & $-17.4 \%$ & $-27.2 \%$ & $-56.7 \%$ \\
SD+1 & $10.7 \%$ & $12.8 \%$ & $16.3 \%$ & $23.3 \%$ & $44.3 \%$ \\
SD+2 & $17.5 \%$ & $21.3 \%$ & $27.6 \%$ & $40.2 \%$ & $78.0 \%$ \\
Risk/return ratio & 1.69 & 1.91 & 2.20 & 2.60 & 3.16 \\
Median & $3.9 \%$ & $4.4 \%$ & $5.1 \%$ & $6.5 \%$ & $10.8 \%$ \\
Kurtosis & 1.05 & 1.04 & 1.04 & 1.03 & 1.03 \\
Skewness & 0.30 & 0.27 & 0.24 & 0.21 & 0.17 \\
Range & $43.5 \%$ & $54.5 \%$ & $72.7 \%$ & $109.2 \%$ & $218.6 \%$ \\
Min & $-15.3 \%$ & $-20.0 \%$ & $-27.9 \%$ & $-43.6 \%$ & $-90.8 \%$ \\
Max & $28.2 \%$ & $34.5 \%$ & $44.8 \%$ & $65.6 \%$ & $127.9 \%$ \\
\hline
\end{tabular}

Table 1 highlights the average ungeared quarterly total returns of $4.0 \%$ and a high standard deviation of $6.8 \%$. This indicates that the data points are spread out over a large range of values as evident by the maximum (28.2\%) and minimum (-15.3\%) quarterly returns which are well outside \pm 2 standard deviations. Interestingly, this spread is not supported by a relatively high 1.05 excess Kurtosis reading which suggests the data are clustered close to the mean with some values lying at the extremities of the distribution. This gives an impression that the data appear to be taller and narrower than a normal distribution with fatter (heavier) tails.

In addition, Table 1 shows the average returns increases with higher gearing levels. An $80 \%$ gearing level can lead to long term $140 \%$ improvement in the residential property total returns, although the risk has increased five-fold. This is evident when examining the range of maximum and minimum returns, an $80 \%$ gearing level has a range of $128 \%$ compared to the ungeared property total return range of $28 \%$. In the $80 \%$ gearing level, the large negative return of $-98 \%$ would represent a substantial drop in value, over 50\%, and increases the chance that the residential property will be in loan default with the possibility of the investor losing the property and their equity.

Also the investment profile changes substantially from the ungeared property total return risk/return ratio of 1.69 to the higher risk/return ratio of 3.16 at the $80 \%$ gearing level. The increased risk can have a major impact on the inclusion of geared property in a mixed asset 
portfolio. This is evidenced by risk adverse self-managed superannuation funds preference for low geared residential property investments (ASIC 2016).

In detailing descriptive statistics, the number of these extreme values outside \pm 2 standard deviations gives a dumb bell feature (fat tails) to the asymmetric bell curve distribution. This is a common characteristic when examining extreme risk, most importantly on the left side of the distribution covering the dangerous downside values, which more often highlight events leading to financial ruin. As the negative distribution is important to examining downside risk, Table 2 compares the actual downside quarterly residential property total return values to the standard bell curve distribution from the mean. Interestingly the variation remained nearly constant across the different gearing levels.

Table 2

Downside Risk Comparison: Normal Bell Curve Distribution Values to the Ungeared Quarterly Residential Property Total Return

\begin{tabular}{lccc}
\hline & Normal Distribution & Actual Data & Variation \\
\hline Mean to -1SD & 56 & 58 & 2 \\
-1SD to -2SD & 21 & 18 & -3 \\
-2SD to -3SD & 3 & 4 & 1 \\
-3SD $>$ & 0 & 0 & 0 \\
\hline
\end{tabular}

Table 2 compares the spread of the 80 actual data points to that for a standard bell curve distribution. It is evident that there is a lack of actual data points between -1SD and -2SD data with the excess occurring close to the mean and on the extremities (beyond -2SD). This highlights the contrast between stable market conditions and periods of large negative price movements.

The location of the four downside outliers (beyond -2 standard deviations) in the residential property time series appeared independent although they occurred in the September quarter being in order 1987, 19811982 and 1989. Interestingly the 1980s covered period of sharp rises in already high interest rates. Extreme risk with single outliers in isolation should be viewed together with surrounding data.

The periods of extreme risk can be magnified in the residential property markets in relation to individual property performance, these factors include:

i. Short term leases. Unlike many illiquid asset classes with long leases (for example: infrastructure and commercial property), residential property leases are normally for a short $6-12$ months. Tenant turnover should be minimised as can lead to temporary loss of income. This is especially relevant in a competitive marketplace with high vacancy rates. 
ii. Maintenance and Obsolescence. Whilst residential property are immobile, long lasting and capital intensive, there is uncertainty as finishes, design and structure can become dilapidated and ineffective. If overlooked, decay and obsolescence limited usability and occupant satisfaction and so lead to a loss of building performance.

In identifying the actual ungeared property data spread, the likelihood of the extreme values occurring beyond minus 2 standard deviations on a normal bell curve distribution can be measured by a Z-test for un-geared and geared property data alongside the Cubic Power Law distribution model. For the 40 years of actual quarterly data, Table 3 shows the probability of the four outermost values occurring compared to the Cubic Power Law application.

Table 3 Event Probability - Standard Bell Curve Distribution and
Cubic Power Law Distribution

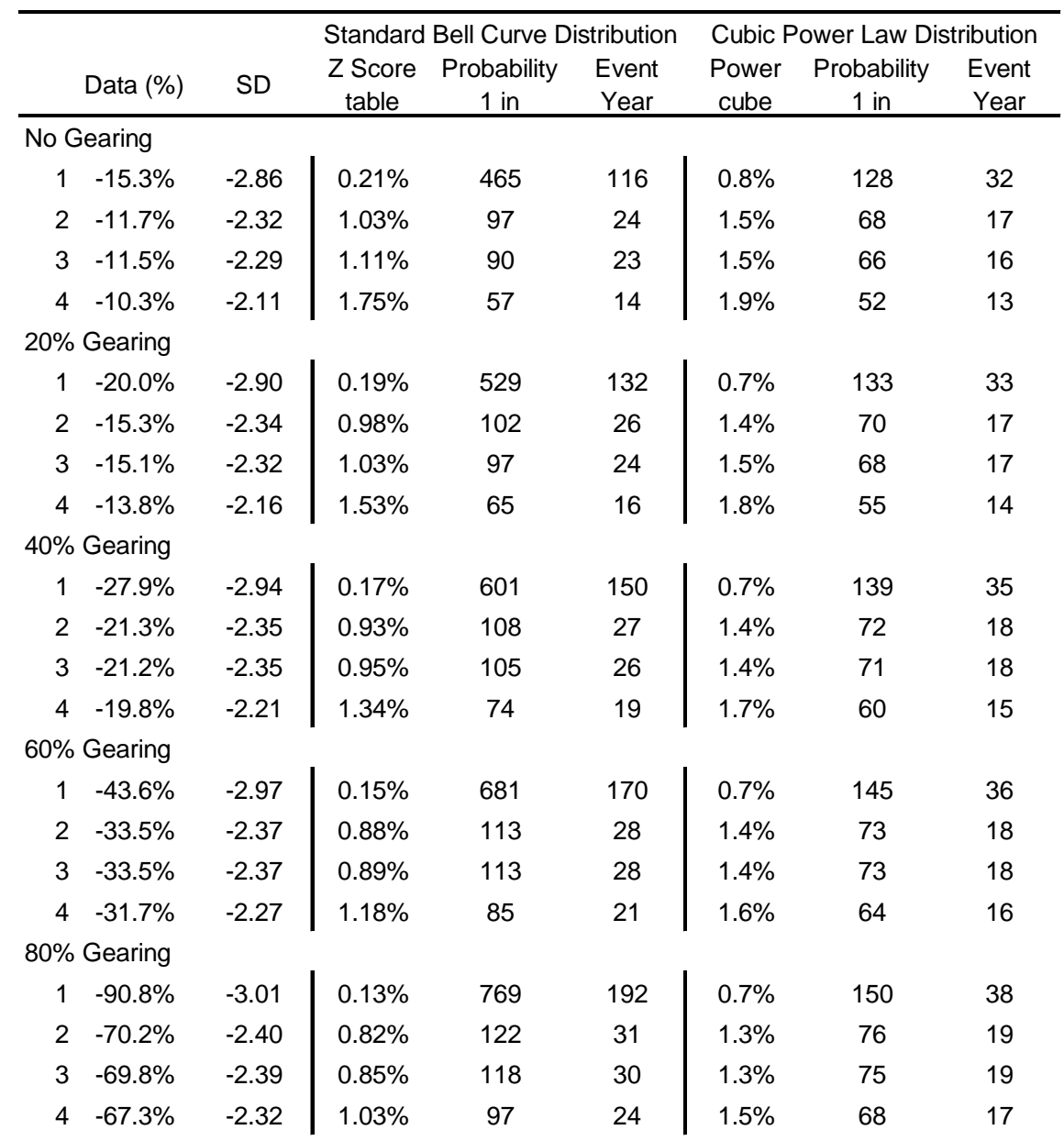

Table 3 points to a disconnect between the standard bell curve distribution and the actual residential property market total returns. The furthest actual ungeared negative value $-15.3 \%$ represents a -2.86 standard deviation reading, which on the $Z$ test table for a one tailed downside distribution shows a 1 in 465 chance of the event occurring, being an unrealistic 1 in 116 year 
event. Alternatively, the Cubic Power Law of returns illustrate the probabilities of extreme events occurring are substantially improved to realistic levels. For the extreme outlier, there is a 1 in 128 chance of the event occurring, being a realistic 1 in 32 year event. Below -2 standard deviation, a Cubic Power Law reading converges to the normal distribution curve.

Conversely, taking the calculated means and standard deviation for the 40 years of actual quarterly residential property market total returns ungeared and geared, the $Z$ test for a one tailed downside distribution calculates the furthest negative value. See Table 4 for the furthermost actual and generated outlier.

Table 4

Actual and Generated Extreme Outlier

\begin{tabular}{lccc}
\hline & Actual & Generated & Difference \\
\hline No Gearing & $-15.3 \%$ & $-14.8 \%$ & $3.4 \%$ \\
$20 \%$ Gearing & $-20.0 \%$ & $-18.1 \%$ & $10.5 \%$ \\
$40 \%$ Gearing & $-27.9 \%$ & $-25.4 \%$ & $9.7 \%$ \\
$60 \%$ Gearing & $-43.6 \%$ & $-38.9 \%$ & $12.0 \%$ \\
$80 \%$ Gearing & $-90.8 \%$ & $-78.7 \%$ & $15.3 \%$ \\
\hline
\end{tabular}

Table 4 highlights the difference between the ungeared $Z$ test for a one tailed downside distribution calculates the furthest negative value at $-14.8 \%$. This is a $3.4 \%$ difference to the actual worst negative value of $-15.3 \%$. As the gearing level increases the difference between the furthest actual outlier and the generated data outlier increases to $15.3 \%$. This shortfall highlights the limitations of the standard deviation model for a measure of extreme risk where the data exhibits asymmetric fat tailed distribution features.

While scalable laws do not yet yield precise results, Cubic Power Law model can be an extremely robust method to identify the performance of an investment to the vulnerability to severe risk, where extreme values are more common than a normal distribution implies. This fundamentally quantifies distributions that have "fat tails", namely, a higher probability of extreme values that can have a significant impact on long term performance (Mandelbrot and Taleb 2006).

Whilst this research examines residential property returns, the asset class should not be considered in isolation as alternative investments could exhibit similar features. This is evident by Mandelbrot and Hudson (2008), Silver (2013) and Weatherall (2013) research on the American stockmarket, all showing that a normal bell curve distribution does not effectively account for extreme price movements and that equity markets are wildly random.

For residential property, extreme downside risk provides a challenge especially with small Australian investors attracted to high gearing levels. The traditional risk management techniques are to narrow and constraining to identify the implication at a market level, particularly the small investor exposure to interest rate movements and separably the implications of individual property 
features. Property professionals need a measure of extreme risk as the first step to analysing and managing potential risks which can limit small investors experiencing unexpected financial ruin.

\section{Conclusion}

Standard deviation is a recognised mathematical indicator which forms one of the key statistical approaches for the banking and finance community to measure and compare risk performance across asset classes. Whilst the standard deviation model work well in theory, under stable conditions, it fails when stable assumptions cease to hold and extreme volatility occurs. This is evident in residential property markets which can experience extended stable periods and major unpredictable events, creating large concentrated negative price fluctuations which may not be reflected in standard risk calculations.

This research studies 40 years of quarterly Melbourne residential property market performance data for normal distribution features and signs of extreme downside risk. The results show that the data appears to be asymmetric, being taller and narrower than a normal bell curve distribution with fat dumb bell tails at the left perimeter. There is a disconnect between the standard bell curve distribution and the actual residential property market total returns. This is demonstrated by the furthest actual ungeared negative value $-15.3 \%$ representing the probabilities of an unrealistic 1 in 116 year event occurring. Alternatively, the Cubic Power Law of returns substantially improved the probabilities of extreme events occurring with a realistic 1 in 32 year event.

The application of a cubic power law distribution model from statistical physics provides an insightful and robust method to identify the performance of an investment to the vulnerabilities of severe risk. Analysis of extreme downside risk should form a key part of the residential decision process, as the traditional risk management practices are too narrow and constraining a definition. Measuring extreme risk and the likelihood of ruin is an important initial step for market participants especially where individual residential property investors have a large debt exposure which can lead to financial ruin.

\section{References}

ABS, 2015, Residential Dwellings: Values, Mean Price and Number by State and Territories, Australian Bureau of Statistics, Canberra.

ASIC, 2015, Borrowing to Invest, ASIC Money Smart: Financial Guide you can Trust, Australian Securities and Investments Commission, Sydney.

Bodman P and Crosby N, 2004, Can Macroeconomic Factors Explain High House Prices in Australia, Australian Property Journal, Vol. 38, No 3, p175-179.

Buchanan M, 2013, Forecast: What Physics, Meteorology and the Natural Sciences Can Teach Us About Economics, Bloomsbury, London. 
Case K and R Shiller (1989), The Efficiency of the Market for Single-Family Homes, The American Economic Review, Vol. 79, Iss1, p 125-137.

Damodaran A, 2008, Strategic Risk Taking: A Framework for Risk Management, Wharton School Publishing, New Jersey.

Gabaix X, 2008, Power Laws in Economics and Finance, NBER Working Paper 14299, Cambridge, Massachusetts.

Heaney R, Higgins D and Di loria A, 2012, Investment Portfolios and the Three Dimensions of Real Estate Investment, Pacific Rim Property Research Journal, Vol 18, No 4, p 445-467.

Higgins D, 2014, The Value of Debt on Property Investment Market Performance, Pacific Rim Property Research Journal, Vol 20, No1, p 45-54.

Higgins D, 2015, Defining the Three Rs of Commercial Property Market Performance: Return, Risk and Ruin, Journal of Property Investment and Finance, Vol. 33, Iss 6, p481-493.

Lux T, 2006, Financial Power Laws: Empirical Evidence, Models, and Mechanism, Working paper, Department of Economics, University of Kiel.

Malevergne $Y$ and Sornette D, 2006, Extreme Financial Risks: From Dependence to Risk Management, Springer, Berlin.

Mandelbrot B and Hudson R, 2008, The (mis)Behaviour of Markets: A Fractal View of Risk, Ruin and Reward, Profile Books, London.

Mandelbrot B and Taleb N, 2006, A Focus on the Exceptions that Prove the Rule, Financial Times, March 23, p40.

Powell R, 2008, Measuring Extreme Financial Risk with Power Laws, Bank Accounting and Finance, Feb/Mar, Vol. 21, p31-36.

Kohler M and van der Merwe, 2015, Long-run Trends in Housing Price Growth, Reserve Bank of Australia Bulletin, Sept Quarter, p21-30

RBA, 2014a, Submission to the Financial System Inquiry, Reserve Bank of Australia, Sydney, April.

RBA, 2014b, Households' Investment Property Exposures: Evidence from Tax and Survey Data, Reserve Bank of Australia Bulletin, Sydney, Sept.

Silver N, 2012, The Signal and the Noise: Why So Many Predictions Fail - But Some Don't, The Penguin Press, New York.

Taleb N, 2009, The Black Swan: The Impact of the Highly Improbable, 2nd edit, Penguin Book, London.

Trahan F and Krantz K, 2011, The Era of Uncertainty: Global Investment Strategies for Inflation, Deflation and the Middle Ground, John Wiley \& Son, New Jersey.

Weatherall J, 2013, The Physics of Finance, Predicting the Unpredictable: Can Science Beat the Markets, Short Books, London.

Wheelan C, 2013, Naked Statistics: Stripping the Dread from the Data, W.W. Norton and Company, New York. 